\title{
Diet as Adjunctive Treatment for Inflammatory Bowel Disease: Review and Update of the Latest Literature
}

Oriana M. Damas, MD*

Luis Garces, RD

Maria T. Abreu, MD

\author{
Address \\ "Division of Gastroenterology, University of Miami Miller School of Medicine, \\ Clinical Research Building (CRB) Rm 971, 1120 NW 14th Street, Miami, FL, \\ 33136, USA \\ Email: odamas@med.miami.edu
}

Published online: 9 April 2019

(C) The Author(s) 2019

This article is part of the Topical Collection on Inflammatory Bowel Diseases

Keywords Diet · Inflammatory bowel disease $\cdot$ Nutrition $\cdot$ Crohn's disease $\cdot$ Ulcerative colitis

AbstractPurpose of review Diet plays an integral role in development of inflammatory bowel disease (IBD) and continues to act as a mediator of intestinal inflammation once disease sets in. Most clinicians provide little dietary guidance to IBD patients, in part due to lack of knowledge in nutrition and lack of available nutritional resources. The purpose of this review is to provide clinicians with a brief summary of the latest evidence behind diets popular among IBD patients, to highlight diets with known efficacy, and to provide guidance that may help busy practitioners.

Recent findings The latest studies show that exclusive enteral nutrition (EEN) remains the most effective diet for induction of remission in Crohn's disease (CD), either in the form of elemental, semi-elemental, or polymeric formulas. Recent studies also show that EEN can be useful in complicated CD including in enterocutaneous fistulas closure and to optimize nutrition in the pre-operative setting. Although new studies suggest that partial enteral nutrition supplemented with elimination diets may be beneficial in ulcerative colitis (UC) and $C D$, larger controlled studies are needed to support their use. The autoimmune diet also shows promise but lacks larger studies. Recent uncontrolled clinical studies evaluating the specific carbohydrate diet (SCD) suggest that this diet may improve biochemical markers of inflammation and induce mucosal healing, although larger studies are needed to support its use, especially because the SCD is very restrictive. Short-term use of the low FODMAP diet is appropriate when in the setting of an acute flare up and/or in stricturing disease, but long-term restriction of FODMAPs is not recommended given long- 
term changes observed in the microbiome. Recent studies suggest that avoidance of processed foods, packaged with preservatives and emulsifiers, may be important in decreasing intestinal inflammation; many of the recent popular diets share a common concept, avoidance of processed foods.

Summary In this review of the latest literature, we highlight that dietary studies are still in a rudimentary stage. Large prospective randomized control studies are underway evaluating head to head comparisons on the efficacy of some of these diets. We offer general guiding principles that may help gastroenterologists in the meantime.

\section{Introduction}

Food choices are central concerns to patients living with inflammatory bowel disease (IBD) and yet very few providers address diet during office visits. Lack of dietary guidance in the office is primarily a consequence of visit time constraints, lack of knowledge in nutrition, and limited available dietary guidelines based on prospective data. However, over the last few years, we have witnessed a renewed interest in the study of diet as a cause and treatment for IBD. This is led primarily by a better understanding of the integral role of the microbiome in IBD pathogenesis and how diet can in turn impact the biodiversity and functionality of the microbiome. The global increase in incidence and prevalence of IBD also suggests a strong and evolving environmental exposure, wherein diet and westernization of diet are plausible culprits to help explain patients' susceptibility to IBD. In this review, we focus on newly available clinical studies performed within the last 34 years and summarize evidence-based dietary recommendations. We focus on dietary recommendations for patients with IBD that may serve as clear guidance to busy gastroenterologists in their practice.

\section{Broad concepts}

As a general recommendation, patients should be cautioned about ongoing consumption of a typical Western diet pattern: a diet high in animal protein, dairy, high fat, high wheat, and processed foods. Besides these proinflammatory food groups, processed foods are particularly harmful because they contain emulsifiers, preservatives, and/or thickeners that cluster together as part of industry-added ingredients $[1 \bullet \bullet$. These ingredients are difficult to measure and in mouse models are implicated with colitis development [2]. Food additives such as carrageenans found in dairy and maltodextrin, a thickener found in many packaged foods, have been implicated in IBD development $[1 \bullet \bullet]$. There are also epidemiologic studies that demonstrate an increased risk of Crohn's disease (CD) and ulcerative colitis (UC) in populations who consume a high Western diet $[3,4]$. Further, we see a lower risk of UC and CD in patients who consume a prudent diet, consisting of a diet high in fiber in the form of fruits and vegetables, and low in animal fat, dairy, and processed foods [3, 4]. The diets selected in this review all share in common similar elements of what is considered a "prudent" diet and we show evidence for the efficacy of these diets in the paragraphs below. Diets were selected based on the popularity of these diets among patients and we also tried to focus on diets with available published clinical trials, rather than single case series or hypothetical data. As of this 
review, the field still lacks adequately powered high-quality studies, so many of the studies available are either uncontrolled clinical studies or small sample randomized controlled studies. Last, we briefly review the latest evidence available for popular nutritional supplements (Table 1).

\section{Diets to control inflammation and symptoms}

\section{Enteral nutrition and partial enteral nutrition}

We chose to discuss an enteral diet because of its demonstrated efficacy as a steroid-sparing agent in the treatment of Crohn's disease $[1 \bullet \bullet]$. Exclusive enteral nutrition (EEN) is not effective for UC. EEN is intake of only liquid formulas without the intake of foods usually for a period of 6-8 weeks. It can involve different protein sources and can be classified into three types: elemental (amino acid based), semi-elemental (oligopeptides), and polymeric (whole protein based) formulas. These are hypoallergenic formulas that result in decreased antigen exposure in the intestine. All have similar efficacy [5]. Recent pediatric studies, where the large body of research exists, find that EEN can induce remission in $60-86 \%$ of children resulting in decreased biochemical markers of inflammation (CRP, ESR, and fecal calprotectin) [5, 6•, 7-9]. This is particularly attractive in pediatrics, because intake of EEN can replace steroid use and therefore result in better bone growth and child development. A recent open-label non-placebo-controlled pediatric study assessed achievement of mucosal healing with the use of 8 weeks of EEN in combination with azathioprine and found mucosal healing was observed in 33\% of patients [9].

However, some challenges to the use of EEN, especially in adults, are its poor tolerability given its taste, and the fact that despite effective remission rates, long-term outcomes like prevention of relapse or complications are no different than with use of steroids $[1 \bullet \bullet]$. To tackle the issue of poor taste, researchers have looked into partial EEN when in combination with dietary therapies [10]. Research groups have employed strategies to either use high-volume enteral nutrition (77\% energy intake) with ad lib food intake or specific food-group exclusion diets, in order to allow patients free food intake while at the same time providing nutrition through enteral feeds. These studies unfortunately show that intake of some whole foods and partial EEN was not as effective as EEN [11]. One study found similar remission rates in patients treated with either infliximab or EEN (ranging from 73 to 76\%) compared to a lower rate in patients treated with partial enteral nutrition (at 50\%) [5]. Similarly, fecal calprotectin measurements were lower $(<250 \mathrm{mcg} / \mathrm{ml})$ in those treated with EEN (45\%) compared to those treated with partial enteral nutrition (14\%). In mild to moderate luminal CD, partial enteral nutrition with adjunctive whole foods following the CD-elimination diet (described in detail below) found clinical remission rates of $70 \%$ in children and $69 \%$ in adults, with normalization of CRP in $70 \%$ of patients in remission [12].

Recent studies conducted demonstrate that EEN can be useful in the setting of complicated CD with either inflammatory strictures or enterocutaneous fistulas. In one prospective CD study, 65 patients with inflammatory strictures were included and given EEN therapy for 12 weeks. Among patients who completed the EEN (50 patients, $84.7 \%$ of participants), inflammatory strictures were noted to improve using average luminal cross-sectional area at the site of the stricture on cross-sectional imaging [13]. Similarly, in a study including 48 CD 
Table 1. Studied popular diets

\begin{tabular}{|c|c|c|c|}
\hline Diet & Components of diet & Evidence & Our recommendations \\
\hline EEN diet & Liquid oral nutrition supplements & $\begin{array}{l}\text { Prospective study } \\
\text { Retrospective case } \\
\text { control } \\
\text { Retrospective }\end{array}$ & $\begin{array}{l}\text { Appropriate to use for severe } C D \\
\text { patients including those with } \\
\text { fistulizing disease and } C D \text { patients } \\
\text { with obstructive symptoms prior to } \\
\text { surgery }\end{array}$ \\
\hline CD exclusion diet & $\begin{array}{l}\text { Only whole foods (food that has } \\
\text { been minimally processed or refined } \\
\text { and is free from additives } \\
\text { or other artificial substances), } \\
\text { with exclusion of certain foods }\end{array}$ & $\begin{array}{l}\text { Observational } \\
\text { study }\end{array}$ & $\begin{array}{l}\text { Promising approach for patients with } \\
\text { severe } C D \text { with loss of response to } \\
\text { biologics }\end{array}$ \\
\hline $\begin{array}{l}\text { Specific } \\
\text { carbohydrate } \\
\text { diet }\end{array}$ & $\begin{array}{l}\text { Restricts processed foods and } \\
\text { certain carbohydrates (grains) }\end{array}$ & $\begin{array}{l}\text { Case series } \\
\text { Prospective } \\
\text { Retrospective }\end{array}$ & $\begin{array}{l}\text { Currently not recommended due to lack } \\
\text { of large controlled studies and lack of } \\
\text { evidence that leads to mucosal } \\
\text { healing }\end{array}$ \\
\hline $\begin{array}{l}\text { Autoimmune } \\
\text { diet }\end{array}$ & $\begin{array}{l}\text { Modified Paleolithic diet, excludes } \\
\text { gluten and dairy }\end{array}$ & $\begin{array}{l}\text { Open-label } \\
\text { observational } \\
\text { study }\end{array}$ & $\begin{array}{l}\text { Promising however lacking significant } \\
\text { studies }\end{array}$ \\
\hline Low FODMAP diet & $\begin{array}{l}\text { Avoidance of certain short-chain } \\
\text { carbohydrates found in some foods } \\
\text { that are poorly digested and } \\
\text { absorbed leading to water being } \\
\text { pulled into the intestinal lumen or } \\
\text { fermentation by gut bacteria }\end{array}$ & $\begin{array}{l}\text { Pilot study } \\
\text { Randomized, } \\
\text { double-blind, } \\
\text { placebo-controlled, } \\
\text { cross-over, } \\
\text { rechallenge trial } \\
\text { Clinical practice }\end{array}$ & $\begin{array}{l}\text { Recommend low FODMAP for patients } \\
\text { with active GI symptoms or with } \\
\text { stricturing/fibrostenosing disease }\end{array}$ \\
\hline $\begin{array}{l}\text { Curcumin } \\
\text { supplementation }\end{array}$ & 2-3 g daily & $\begin{array}{l}\text { Case reports } \\
\text { Case series } \\
\text { Randomized } \\
\text { controlled trials }\end{array}$ & $\begin{array}{l}\text { Recommended for patients with mild to } \\
\text { moderate UC }\end{array}$ \\
\hline $\begin{array}{l}\text { Omega-3 } \\
\text { supplementation }\end{array}$ & 4 g daily & $\begin{array}{l}\text { Pilot study } \\
\text { Observational } \\
\text { Double-blind, } \\
\text { randomized, } \\
\text { placebo-controlled } \\
\text { trial }\end{array}$ & Currently not recommended \\
\hline $\begin{array}{l}\text { Vitamin D } \\
\text { supplementation }\end{array}$ & 50,000 IU weekly & Meta-analysis & $\begin{array}{l}\text { 50,000 IU weekly if deficient, } \\
\text { confirmed by laboratory results }\end{array}$ \\
\hline
\end{tabular}

patients with enterocutaneous fistulas who were treated with short-peptide based EN for 3 months, there was successful closure of E-C fistulas in $62.5 \%$ of patients [14]. Finally, there is also a growing body of evidence indicating that EEN can be used in the pre-operative setting to prevent post-operative complications or even surgery altogether $[15,16]$. In one retrospective cohort, 13 out of 51 patients $(25 \%)$ were able to avoid surgery for intestinal resection after employment of EEN for 6 weeks [15]. In those that did progress, EEN prevented post-op abscess 
formation or leakage to a greater extent than those who did not use EEN. Other studies show similar reduction in post-op complications, including of endoscopic recurrence in the post-op setting $[17,18]$. Taken altogether, EEN is effective as induction therapy for severe $\mathrm{CD}$ and can be helpful in prevention of post-op complications, as well as in fistula and stricture closure in complicated CD patients. EEN as long-term therapy however remains a challenge given its lack of palatability and also lack of data looking at efficacy of EEN as maintenance.

In our adult practice, we reserve the use of EEN with semi-elemental or polymeric formulas to patients with severe $\mathrm{CD}$, including those with fistulizing disease (for example in those with enterocutaneous fistulas), who are having difficulty achieving clinical and biochemical response despite aggressive biologic therapy. EEN can also be helpful to optimize nutrition in those with severe CD especially with obstructive symptoms that need surgery. More commonly, we recommend generic formulas such as Boost or Ensure as well as specialty formulas free of common allergens (gluten, soy, dairy, corn, preservative free) such as Orgain or Kate Farms for severely ill patients with aggressive disease and who cannot meet their caloric intake because of symptoms as an adjunct to aggressive medical therapy, e.g., biologics.

The CD exclusion diet was developed to allow only access to whole foods, with exclusion of foods that presumably alter host barrier function, result in dysbiosis, and influence bacterial/viral factors that allow bacterial translocation. The food items excluded are hypothesized to alter the microbiome or intestinal permeability. Inflammatory food items excluded in this diet include wheat, dairy, emulsifiers, maltodextrins, carrageenans, and sulfites. There are only two uncontrolled clinical studies in the literature that have examined this diet, both with promising results in a total of 68 patients. In the first study, a total of 47 children and young adults were given partial EN with CD-elimination diet for a period of 6 weeks. Disease activity scores were used and CRP was measured at baseline and the end of the study. Crohn's disease activity index decreased from 27.7 to $5.4(p<.001)$ and CRP normalized in 21 of the 30 patients found to be in clinical remission [12]. In a more recent study, $21 \mathrm{CD}$ patients were included who had loss of response to biologics. These patients were given partial EN with 12 weeks of a CD exclusion diet. These patients with severe flares were given an initial 14 days of EEN followed by partial EN with a polymeric formula and the CD-elimination diet for 12 weeks. Clinical remission rates after 6 weeks were reported at $61.9 \%$ with normalization of CRP and albumin levels as well.

Administration of partial EN with a CD-elimination diet is a promising approach for patients with severe CD, in those with loss of response to therapeutic doses of biologics. Larger studies with randomization and comparison groups, including a control group with exclusive intake of EEN, or only the elimination diet, are needed before we can recommend this diet more broadly. In general, the additives targeted for elimination make biological sense to avoid in IBD patients (possibly in many people!). We will discuss wheat below. 
early 1920s for the treatment of celiac disease and has found its way as a diet therapy for the IBD population. It is one of the most popular diets in IBD yet evidence for its efficacy in controlling inflammation is still lacking. It is also a very strict diet that is difficult to maintain. The diet consists of consuming monosaccharides, with restricted intake of polysaccharides and disaccharides (excluding sucrose and certain starches). It allows almost all fruits, some vegetables, nuts, meats, and eggs and avoids as mentioned certain starches (specifically all grains), table sugar, and most preservatives/food additives as well as dairy (except for fermented yogurts and hard cheeses). Several retrospective studies and case series have demonstrated improvement of clinical disease activity scores and biochemical markers of inflammation including CRP, fecal calprotectin, and normalization of serum albumin [19, 20]. A prospective study examined for the first time whether the SCD administered over 52 weeks led to mucosal healing as evidenced by administration of capsule endoscopy at the completion of the study. Out of the 10 pediatric CD patients, a total of 4 achieved mucosal healing by the end of the study and 8 of the 10 showed significant mucosal improvement using the Lewis score [21].

More recently, a prospective non-placebo-controlled study followed the clinical disease activity, biochemical markers, and gut microbiome composition of pediatric CD patients who agreed to consume a SCD for 12 weeks. At the study completion, the authors noted that CRP and clinical disease activity improved in all 12 recruited patients. Serum albumin levels in patients also normalized by the end of the 12-week period. Interestingly, although no clear dysbiosis was observed as a pattern in the 7 patients with stool available for sequencing, the overall diversity of the flora after 12 weeks on the SCD did shift towards gut flora of controls [22]. The above uncontrolled clinical studies suggest that symptomatic and biochemical improvement is present in CD and UC patients exposed to a specific carbohydrate diet. There are now small studies looking at mucosal healing in patients on a SCD and not all of them show that gut inflammation improved. A recent retrospective study of 7 patients showed that, despite improvement and/or normalization of albumin, CRP, stool calprotectin, and hematocrit, patients on a SCD did not achieve complete mucosal healing (defined as the absence of any ulceration) after an average of 26 months [23]. Given the variability of design and the small sample data available to date, these prior studies should be considered preliminary results wherein larger prospective controlled trials are needed to validate this data. At the present time, there are several randomized controlled trials examining the SCD and we should expect results in the coming years. One specifically compares the efficacy of the SCD to the Mediterranean diet in a multicenter RCT (clinical trial NCT03058679).

The anti-inflammatory diet, a modified version of the SCD, is sometimes advocated by patients, but thus far, only a small case series looking at the beneficial impact of this diet has been published [24]. The development of the anti-inflammatory index demonstrated the association between diet and how it can positively or negatively affect CRP, which has been used as a marker of inflammation in conditions such as rheumatoid arthritis as well as many others [25].

In our adult practice, we do not currently recommend the SCD in our practice due to the lack of controlled studies validating its efficacy in achieving 
mucosal healing. While there are elements of this diet, such as avoidance of processed foods, that we consider important, the restrictiveness of this diet usually results in weight loss and ultimately difficulty with adherence. In those who still chose to be on the SCD, we monitor for vitamin D deficiency, which can be especially deficient in IBD patients following this diet [26].

The autoimmune diet

The autoimmune diet is a modified Paleolithic diet which includes avoidance of gluten and dairy. The dietary instructions are to first initiate an elimination phase and once clinical symptoms and inflammation are controlled, the autoimmune diet includes a 5-week maintenance phase followed by eventual reintroduction of foods, one at a time, in order to allow identification of trigger items. The initial phase requires elimination of several items: grains, processed sugars, oils, alcohol, caffeine, nuts, dairy, eggs, and even legumes. In one openlabel observational study, the authors evaluated the efficacy of an autoimmune in patients with UC or CD with evidence of clinical and objective evidence of inflammation (biochemical/imaging/endoscopic inflammation). A total of 15 patients completed the study, 9 with CD and 6 with UC. Participants were coached on an autoimmune diet and clinical symptoms as well as markers of inflammation, CRP, fecal calprotectin, and when available endoscopic inflammation were assessed [27]. The authors found that even in this small subset of patients, there was improvement in their clinical symptoms and in their quality of life scores, with $73 \%$ achieving clinical remission in a 6-week period, as well as a decrease in fecal calprotectin. All 11 of the 15 maintained remission during maintenance phase.

In our adult practice, we do not recommend this diet at this time. The autoimmune diet is promising but there are insufficient studies to support its use.

\section{Diets that control functional symptoms in IBD}

\section{Low FODMAP diet}

Initially pioneered for IBS patients, the low FODMAP (fermentable oligosaccharides, disaccharides, monosaccharides, and polyols) diet has now emerged as a possible diet for IBD patients. Overall, studies show improvement in clinical symptoms in patients using a low FODMAP diet, but there is no evidence of improved inflammation. In a small randomized control study of 9 patients with clinically quiescent $\mathrm{CD}$, patients were randomized into a diet low in FODMAP or a diet containing FODMAPs. At the end of the study period, there were no differences in fecal calprotectin between those on the low FODMAP or the standard FODMAP containing diet, suggesting no improvement in luminal inflammation [28].

A recent study published examined the impact of a 6-week low FODMAP diet on IBD symptoms in 88 patients. Seventy-eight percent of patients reported relief of their symptoms based on the Gastrointestinal Symptom Rating Scale. A significant reduction in the severity of abdominal pain, bloating, flatulence, belching, incomplete evacuation, nausea, and heartburn was observed as well as an increase in patients reporting normal stool consistency using the Bristol Stool Form Scale $(55 / 88,63 \%)$. There was no specified medication exclusion 
including that patients could have been on steroids [29•]. Similarly, in 2017, a randomized, double-blind study with 29 confirmed IBD patients examined the effects of FODMAPs on gastrointestinal symptoms. The study reintroduced fructans, galacto-oligosaccharides, and sorbitol over a 3-day rechallenge period as well as glucose placebo while monitoring functional gastrointestinal symptoms. There was an increase in GI symptoms during the final day of the fructans challenge. Finally, a recent meta-analysis concluded that employment of a low FODMAP diet is effective for reduction of GI symptoms in patients with quiescent IBD [30].

While a low FODMAP diet may be beneficial in controlling functional symptoms in IBD patients, or in patients with stricturing/stenosing disease, alterations in FODMAP intake (e.g., carbohydrate content) worsen dysbiosis in IBS patients and therefore should not be recommended indefinitely in patients with IBD [31]. While the low FODMAP diet can adequately meet all of a patient's nutritional needs, in the IBD population, a patient's diet may already be limited in what foods they can tolerate, and further affected by the malabsorptive characteristic of IBD, so further restricting the diet may possibly lead to vitamin and mineral deficiencies which should be monitored and supplemented accordingly.

Given the evidence available, in our practice, we recommend the low FODMAP diet in patients with active GI symptoms especially bloating. Additionally, we provide a low FODMAP/low fiber diet in patients with stricturing disease and in those with a recent history of a small bowel obstruction. Finally, a diet low in FODMAP is also provided to patients who have quiescent IBD but superimposed IBS symptoms. Once control of symptoms is achieved, we gradually introduce specific FODMAPs given that patients on low FODMAP diets have decreased Bifidobacterium [32] and greater dysbiosis [31].

Adjunctive therapies

\section{Curcumin supplementation}

Curcumin is a polyphenol derived from the turmeric plant that is thought to contain anti-inflammatory properties and is therefore used commonly as adjunctive therapy to reduce symptoms and/or maintain remission [33]. Several case reports and case series exist dating back to the 2000s detailing its efficacy in decreasing clinical symptoms and CRP and/or ESR levels. There are a total of four RCTs looking at the efficacy of curcumin in IBD. Lang et al. in 2014 found that administration of curcumin (in a compounded formula) at dosages of $3 \mathrm{~g}$ /day in patients with UC on dualroute mesalamines resulted in improvement of disease activity scores and CRP levels measured and greater achievement of remission in the treatment arm [34]. Limitations of this study were a small sample size of 26 in treatment and 24 in the placebo arm, as well as a compounded curcumin formula that is difficult to replicate and/or purchase (there are many available variations of supplements that contain curcuma). A recent RCT study presented in DDW in 2017 found similar results [35]. However, a more recent systematic review of available RCTs found that oral adjuvant curcumin did not contribute to attaining remission in patients with UC [33]. Nevertheless, the verdict on use of curcumin in UC is still out since 
this recent review only examined three small RCTs. Importantly, the most common adverse events reported appear to be mild in nature. Two RCTs reported mild GI-related side effects, including nausea, bloating, and increased stooling in some patients using curcumin [33]. Future large, welldesigned studies are needed to fully conclude whether curcumin is useful in UC and to better define what formula, route, and dosage is effective.

In our practice, we mention use of curcumin in patients with UC with mildmoderate disease, who are in remission or who are experiencing mild symptoms and ask about dietary strategies/alternative regimens to maintain remission. We mention use of it in cooking and if tolerated, in capsule form at the previous dosage studied of $3 \mathrm{~g}$ daily. However, it has been our experience that many patients do experience GI symptoms at greater dosages.

\section{0mega-3 polyunsaturated fatty acid supplementation}

Many IBD patients are curious about the use of omega-3 supplementation, either in the form of foods high in omega-3 or with fish oil supplementation. Two studies looking at the influence of high consumption of omega-3 containing foods showed that patients were more likely to be in clinical remission when high consumption took place. For example, a study looking at high intake of omega-3 using Alaskan salmon found that UC patients who consumed high intake of $600 \mathrm{mg}$ of Atlantic salmon weekly, scored lower in the SCCAI compared to those who did not after 8 weeks $[36 \bullet \bullet]$. Similarly, in another 1 -year study looking at 230 patients, participants whose diet followed a ratio of omega-3/omega- 6 closer to 1 were more likely to be in remission than those following a high omega- 6 diet [37]. It is important to mention to patients however that not all omega-3s have been found to be beneficial. In one study, high dietary intake of alpha linolenic acid (a precursor of long-chain n-3 PUFA) was associated with increased risk of UC relapse whereas total n-3 PUFA without supplementation was protective. Alpha linoleic acid can be found in seeds, such as chia seeds, hemp seeds, and flax seeds. However, this is only the result of one study, and results should of course be interpreted with caution.

Despite the popularity of omega-3 supplementation in the form of fish oil for many chronic diseases, including IBD, the clinical utility of n-3 PUFA supplementation (in the form of fish oil) is not promising. There are several trials looking at consumption of fish oil in UC with varying results available. A randomized, placebo-controlled study administering omega-3 supplementation found that supplements helped with short-term 3-month prevention of UC relapse, but any protective effect was mitigated after 3 years of follow-up [38]. Another study supplementing omega-3 found no difference in UC relapse rates between the treatment group and the control group [39]. A meta-analysis of three trials looking at maintenance of remission in UC with omega-3 supplementation as adjunctive therapy and a recent systematic review looking at prevention of relapse in UC with omega-3 supplementation found no benefit to this supplement [40]. Therefore, we do not recommend omega-3 supplementation in UC.

Similar to UC, recent studies looking at supplementation of omega-3 in patients with CD do not support supplementation. The results of the EPIC-1 
and EPIC-2, two large multicenter RCTs looking at relapse of CD using $4 \mathrm{~g} /$ day of omega-3, found that supplementation is not effective for relapse prevention [41]. A recent meta-analysis of six published trials incorporating 1039 patients found only a small benefit for prevention of relapse with maintenance supplementation, but this study drew conclusions from largely varied studies in design [42].

Since current evidence does not support supplementation with n-3 PUFAs (like fish oil) in IBD, we do not currently recommend this to our patients. Interestingly, because foods naturally high in n-3 PUFAs and low in n-6 PUFAs may be beneficial as suggested by small studies, we recommend a prudent diet that incorporates foods rich in omega-3s. More specifically, we recommend foods high in DPA (docosapentaenoic acid) and DHA (docosahexaenoic acid) omega-3s which include fish like salmon and mackerel.

\section{Vitamin D supplementation}

\section{Conclusion}

Supplementation of vitamin D has potential therapeutic benefit. While still a debate whether low vitamin $\mathrm{D}$ is a contributor of disease or a consequence of it, there are several studies that increasingly highlight an immunoregulatory role for vitamin D. A study by Jorgensen et al. looked at the effect of daily $1200 \mathrm{IU}$ vitamin D supplementation in patients with $\mathrm{CD}$ in remission and showed that after 12 months, patients randomized to receive vitamin D supplementation had lower relapse rates than the control group, despite only a modest increase in vitamin D levels [43]. Similarly, a recent meta-analysis looking at the therapeutic effect of vitamin D supplementation on IBD found that supplementation decreased the rate of disease relapse. This meta-analysis examined data from a total of 18 RTCs, incorporating 908 patients [44].

In our practice, we perform periodic surveillance of vitamin D typically every 5-6 months with aggressive supplementation given the above evidence.

Here we provide a brief summary of emerging diets that may play an important role in the management of IBD. This topic is timely and of pressing importance to our patients. Future multidisciplinary studies are needed to better understand the dietary influences on IBD and in prevention of complications. As we design studies to address the benefits of diet, we must also strategize how we can ensure long-term adherence to potentially beneficial diets.

\section{Compliance with Ethical Standards}

\section{Conflict of Interest}

Luis Garces and Oriana Damas declare no conflict of interest.

Funding for Oriana M. Damas was supported by NIH N3U54MD010722-03S1 and K23DK117054-01A1. 
Funding for Maria T. Abreu was supported by The Micky \& Madeleine Arison Family Foundation Crohn's \& Colitis Discovery Laboratory and Martin Kalser Chair.

Human and Animal Rights and Informed Consent

This article does not contain any studies with human or animal subjects performed by any of the authors.

Open Access This article is distributed under the terms of the Creative Commons Attribution 4.0 International License (http://creativecommons.org/licenses/by/4.0/), which permits unrestricted use, distribution, and reproduction in any medium, provided you give appropriate credit to the original author(s) and the source, provide a link to the Creative Commons license, and indicate if changes were made.

\section{References and Recommended Reading}

Papers of particular interest, published recently, have been highlighted as:

- Of importance

$\bullet \quad$ Of major importance

1.• Levine A, Sigall Boneh R, Wine E. Evolving role of diet in the pathogenesis and treatment of inflammatory bowel diseases. Gut. 2018;67:1726-3.

This paper discusses the role of dietary factors in the pathogenesis of IBD and current gaps in research.

2. Chassaing B, Koren O, Goodrich JK, Poole AC, Srinivasan S, Ley RE, et al. Dietary emulsifiers impact the mouse gut microbiota promoting colitis and metabolic syndrome. Nature. 2015;519:92-6.

3. Ananthakrishnan AN, Khalili H, Song M, Higuchi LM, Richter JM, Nimptsch K, et al. High school diet and risk of Crohn's disease and ulcerative colitis. Inflamm Bowel Dis. 2015;21:2311-9.

4. Racine A, Carbonnel F, Chan SSM, Hart AR, Bueno-deMesquita HB, Oldenburg B, et al. Dietary patterns and risk of inflammatory bowel disease in Europe: results from the EPIC study. Inflamm Bowel Dis. 2016;22:345-54.

5. Lee D, Baldassano RN, Otley AR, Albenberg L, Griffiths $\mathrm{AM}$, Compher $\mathrm{C}$, et al. Comparative effectiveness of nutritional and biological therapy in North American children with active Crohn's disease. Inflamm Bowel Dis. 2015;21:1786-93.

6. Levine A, Turner D, Pfeffer Gik T, Amil Dias J, Veres G, Shaoul R, et al. Comparison of outcomes parameters for induction of remission in new onset pediatric Crohn's disease: evaluation of the porto IBD group "growth relapse and outcomes with therapy" (GROWTH CD) study. Inflamm Bowel Dis. 2014;20:278-8.

The outcomes of this study demonstrated the effectiveness of exclusive enteral nutrition to achieve steroid free clinical remission in CD patients.

7. Connors J, Basseri S, Grant A, Giffin N, Mahdi G, Noble $\mathrm{A}$, et al. Exclusive enteral nutrition therapy in paediatric Crohn's disease results in long-term avoidance of corticosteroids: results of a propensity-score matched cohort analysis. J Crohns Colitis. 2017;11:1063-70.

8. Cohen-Dolev N, Sladek M, Hussey S, Turner D, Veres $\mathrm{G}$, Koletzko S, et al. Differences in outcomes over time with exclusive enteral nutrition compared with steroids in children with mild to moderate Crohn's disease: results from the GROWTH CD study. J Crohns Colitis. 2018;12:306-12.

9. Grover Z, Burgess C, Muir R, Reilly C, Lewindon PJ. Early mucosal healing with exclusive enteral nutrition is associated with improved outcomes in newly diagnosed children with luminal Crohn's disease. J Crohns Colitis. 2016;10:1159-64.

10. Wall CL, Gearry RB, Day AS. Treatment of active Crohn's disease with exclusive and partial enteral nutrition: a pilot study in adults. Inflamm Intest Dis. 2018;2:219-27.

11. Ruemmele FM, Veres G, Kolho KL, Griffiths A, Levine A, Escher JC, et al. Consensus guidelines of ECCO/ESPGHAN on the medical management of pediatric Crohn's disease. J Crohns Colitis. 2014;8:1179207.

12. Sigall-Boneh R, Pfeffer-Gik T, Segal I, Zangen T, Boaz M, Levine A. Partial enteral nutrition with a Crohn's disease exclusion diet is effective for induction of remission in children and young adults with Crohn's disease. Inflamm Bowel Dis. 2014;20:1353-60.

13. Hu D, Ren J, Wang G, Li G, Liu S, Yan D, et al. Exclusive enteral nutritional therapy can relieve inflammatory bowel stricture in Crohn's disease. J Clin Gastroenterol. 2014;48:790-5.

14. Yan D, Ren J, Wang G, Liu S, Li J. Predictors of response to enteral nutrition in abdominal enterocutaneous 
fistula patients with Crohn's disease. Eur J Clin Nutr. 2014;68:959-63.

15. Heerasing N, Thompson B, Hendy P, Heap GA, Walker $\mathrm{G}$, Bethune R, et al. Exclusive enteral nutrition provides an effective bridge to safer interval elective surgery for adults with Crohn's disease. Aliment Pharmacol Ther. 2017;45:660-9.

16. Zheng $X-B$, Peng $X, X i e ~ X-Y$, et al. Enteral nutrition is associated with a decreased risk of surgical intervention in Crohn's disease patients with spontaneous intraabdominal abscess. Rev Esp Enferm Dig. 2017;109:834-42.

17. Wang H, Zuo L, Zhao J, Dong J, Li Y, Gu L, et al. Impact of preoperative exclusive enteral nutrition on postoperative complications and recurrence after bowel resection in patients with active Crohn's disease. World J Surg. 2016;40:1993-2000.

18. Li G, Ren J, Wang G, Hu D, Gu G, Liu S, et al. Preoperative exclusive enteral nutrition reduces the postoperative septic complications of fistulizing Crohn's disease. Eur J Clin Nutr. 2014;68:441-6.

19. Obih C, Wahbeh G, Lee D, Braly K, Giefer M, Shaffer $\mathrm{ML}$, et al. Specific carbohydrate diet for pediatric inflammatory bowel disease in clinical practice within an academic IBD center. Nutrition. 2016;32:418-25.

20. Burgis JC, Nguyen K, Park KT, Cox K. Response to strict and liberalized specific carbohydrate diet in pediatric Crohn's disease. World J Gastroenterol.

2016;22:2111-7.

21. Cohen SA, Gold BD, Oliva S, Lewis J, Stallworth A, Koch B, et al. Clinical and mucosal improvement with specific carbohydrate diet in pediatric Crohn disease. J Pediatr Gastroenterol Nutr. 2014;59:516-21.

22. Suskind DL, Cohen SA, Brittnacher MJ, et al. Clinical and fecal microbial changes with diet therapy in active inflammatory bowel disease. J Clin Gastroenterol. 2018;52:155-63.

23. Suskind DL, Wahbeh G, Gregory N, Vendettuoli H, Christie D. Nutritional therapy in pediatric Crohn disease: the specific carbohydrate diet. J Pediatr Gastroenterol Nutr. 2014;58:87-91.

24. Olendzki BC, Silverstein TD, Persuitte GM, Ma Y, Baldwin KR, Cave D. An anti-inflammatory diet as treatment for inflammatory bowel disease: a case series report. Nutr J. 2014;13:5.

25. Shivappa N, Steck SE, Hurley TG, Hussey JR, Hébert JR. Designing and developing a literature-derived, population-based dietary inflammatory index. Public Health Nutr. 2014;17:1689-96.

26. Braly K, Williamson N, Shaffer ML, Lee D, Wahbeh G, Klein J, et al. Nutritional adequacy of the specific carbohydrate diet in pediatric inflammatory bowel disease. J Pediatr Gastroenterol Nutr. 2017;65:533-8.

27. Konijeti GG, Kim N, Lewis JD, Groven S, Chandrasekaran A, Grandhe S, et al. Efficacy of the autoimmune protocol diet for inflammatory bowel disease. Inflamm Bowel Dis. 2017;23:2054-60.

28. Halmos EP, Christophersen CT, Bird AR, Shepherd SJ, Muir JG, Gibson PR. Consistent prebiotic effect on gut microbiota with altered FODMAP intake in patients with Crohn's disease: a randomised, controlled crossover trial of well-defined diets. Clin Transl Gastroenterol. 2016;7:e164.

29. Prince AC, Myers CE, Joyce T, Irving P, Lomer M, Whelan K. Fermentable carbohydrate restriction (low FODMAP diet) in clinical practice improves functional gastrointestinal symptoms in patients with inflammatory bowel disease. Inflamm Bowel Dis. 2016;22:1129-3.

Improving quality of life can be challenging in the IBD patient population and the results of this study showed improvement in gastrointestinal symptoms in clinical practice in patients following a low FODMAP diet thereby improving their quality of life.

30. Zhan Y-L, Zhan Y-A, Dai S-X. Is a low FODMAP diet beneficial for patients with inflammatory bowel disease? A meta-analysis and systematic review. Clin Nutr. 2018;37:123-9.

31. Bennet SMP, Böhn L, Störsrud S, Liljebo T, Collin L, Lindfors $\mathrm{P}$, et al. Multivariate modelling of faecal bacterial profiles of patients with IBS predicts responsiveness to a diet low in FODMAPs. Gut. 2018;67:872-81.

32. Staudacher HM, Lomer MCE, Farquharson FM, Louis P, Fava F, Franciosi E, et al. A diet low in FODMAPs reduces symptoms in patients with irritable bowel syndrome and a probiotic restores bifidobacterium species: a randomized controlled trial. Gastroenterology. 2017;153:936-47.

33. Grammatikopoulou MG, Gkiouras K, Theodoridis X, Asteriou E, Forbes A, Bogdanos DP. Oral adjuvant curcumin therapy for attaining clinical remission in ulcerative colitis: a systematic review and meta-analysis of randomized controlled trials. Nutrients. 2018. https://doi.org/10.3390/nu10111737.

34. Lang A, Salomon N, Wu JCY, Kopylov U, Lahat A, HarNoy O, et al. Curcumin in combination with mesalamine induces remission in patients with mildto-moderate ulcerative colitis in a randomized controlled trial. Clin Gastroenterol Hepatol. 2015;13:1444-9.e1.

35. Banerjee R, Penmetsa A, Medaboina K, Boramma GG, Amsrala S, Reddy DN. Novel bio-enhanced curcumin with mesalamine for induction of remission in mild to moderate ulcerative colitis. Gastroenterology. 2017;152:S587.

36.• Grimstad T, Berge RK, Bohov P, Skorve J, Gøransson L, Omdal R, et al. Salmon diet in patients with active ulcerative colitis reduced the simple clinical colitis activity index and increased the anti-inflammatory fatty acid index-a pilot study. Scand J Clin Lab Invest. 2011;71:68-73.

While supplementing with omega-3 fatty acids has yet to yield significant results, this study was able to demonstrate the benefit of consistent consumption of food rich in omega-3 fatty acids to improve SCCAI scores.

37. Uchiyama K, Nakamura M, Odahara S, Koido S, Katahira K, Shiraishi H, et al. N-3 polyunsaturated fatty 
acid diet therapy for patients with inflammatory bowel disease. Inflamm Bowel Dis. 2010;16:1696-707.

38. Loeschke K, Ueberschaer B, Pietsch A, Gruber E, Ewe K, Wiebecke B, et al. N-3 fatty acids only delay early relapse of ulcerative colitis in remission. Dig Dis Sci. 1996;41:2087-94.

39. Middleton SJ, Naylor S, Woolner J, Hunter JO. A double-blind, randomized, placebo-controlled trial of essential fatty acid supplementation in the maintenance of remission of ulcerative colitis. Aliment Pharmacol Ther. 2002;16:1131-5.

40. Cabré E, Mañosa M, Gassull MA. Omega-3 fatty acids and inflammatory bowel diseases - a systematic review. Br J Nutr. 2012;107(Suppl 2):S240-52.

41. Feagan BG, Sandborn WJ, Mittmann U, Bar-Meir S, D'Haens $G$, Bradette $M$, et al. Omega-3 free fatty acids for the maintenance of remission in Crohn disease: the EPIC randomized controlled trials. JAMA. 2008;299:1690-7.

42. Turner D, Shah PS, Steinhart AH, Zlotkin S, Griffiths AM. Maintenance of remission in inflammatory bowel disease using omega-3 fatty acids (fish oil): a systematic review and meta-analyses. Inflamm Bowel Dis. 2011; 17:336-45.

43. Ananthakrishnan AN, Khalili H, Higuchi LM, Bao Y, Korzenik JR, Giovannucci EL, et al. Higher predicted vitamin D status is associated with reduced risk of Crohn's disease. Gastroenterology. 2012;142:482-9.

44. Li J, Chen N, Wang D, Zhang J, Gong X. Efficacy of vitamin $\mathrm{D}$ in treatment of inflammatory bowel disease: a meta-analysis. Medicine. 2018;97:e12662.

\section{Publisher's Note}

Springer Nature remains neutral with regard to jurisdictional claims in published maps and institutional affiliations. 